\title{
Feasibility of absolute cerebral tissue oxygen saturation during cardiopulmonary resuscitation
}

\author{
Ingrid Meex ${ }^{1,3^{*}}$, Cathy De Deyne ${ }^{1,3}$, Jo Dens ${ }^{2,3}$, Simon Scheyltjens ${ }^{1}$, Kevin Lathouwers ${ }^{1}$, Willem Boer ${ }^{1}$, \\ Guy Vundelinckx', René Heylen ${ }^{1}$ and Frank Jans ${ }^{1,3}$
}

\begin{abstract}
Introduction: Current monitoring during cardiopulmonary resuscitation (CPR) is limited to clinical observation of consciousness, breathing pattern and presence of a pulse. At the same time, the adequacy of cerebral oxygenation during CPR is critical for neurological outcome and thus survival. Cerebral oximetry, based on near-infrared spectroscopy (NIRS), provides a measure of brain oxygen saturation. Therefore, we examined the feasibility of using NIRS during CPR.

Methods: Recent technologies (FORE-SIGHTTM and EQUANOXTM) enable the monitoring of absolute cerebral tissue oxygen saturation $\left(\mathrm{SctO}_{2}\right)$ values without the need for pre-calibration. We tested both FORE-SIGHTTM (five patients) and EQUANOX Advance ${ }^{\mathrm{TM}}$ (nine patients) technologies in the in-hospital as well as the out-of-hospital CPR setting. In this observational study, values were not utilized in any treatment protocol or therapeutic decision. An independent t-test was used for statistical analysis.

Results: Our data demonstrate the feasibility of both technologies to measure cerebral oxygen saturation during CPR. With the continuous, pulseless near-infrared wave analysis of both FORE-SIGHTTM and EQUANOXTM technology, we obtained $\mathrm{SctO}_{2}$ values in the absence of spontaneous circulation. Both technologies were able to assess the efficacy of CPR efforts: improved resuscitation efforts (improved quality of chest compressions with switch of caregivers) resulted in higher $\mathrm{SctO}_{2}$ values. Until now, the ability of CPR to provide adequate tissue oxygenation was difficult to quantify or to assess clinically due to a lack of specific technology. With both technologies, any change in hemodynamics (for example, ventricular fibrillation) results in a reciprocal change in $\mathrm{SctO}_{2}$. In some patients, a sudden drop in $\mathrm{SctO}_{2}$ was the first warning sign of reoccurring ventricular fibrillation.

Conclusions: Both the FORE-SIGHTTM and EQUANOXTM technology allow non-invasive monitoring of the cerebral oxygen saturation during CPR. Moreover, changes in $\mathrm{SctO}_{2}$ values might be used to monitor the efficacy of CPR efforts.
\end{abstract}

\section{Introduction}

Monitoring the adequacy of oxygenation and circulation in patients during cardiopulmonary resuscitation (CPR) and advanced life support (ALS) remains a major challenge. Monitoring is limited to clinical observation of consciousness, pulse and breathing pattern [1]. During CPR and ALS, pulse oximetry and non-invasive blood pressure measurement are unreliable. Additionally, an intermittent (every two minutes) rhythm check with electrocardiography (ECG)-electrodes or defibrillator paddles necessitates

\footnotetext{
* Correspondence: ingrid.meex@uhasselt.be

'Department of Anesthesiology, Intensive Care, Emergency Medicine \& Pain Therapy, Ziekenhuis Oost-Limburg, Schiepse Bos 6, 3600 Genk, Belgium Full list of author information is available at the end of the article
}

interruption of chest compressions. Currently, end-tidal $\mathrm{CO}_{2}$ measurement is the best technique to monitor adequate circulation; it will increase sharply on return of spontaneous circulation (ROSC). However, end-tidal $\mathrm{CO}_{2}$ can only be used in the intubated patient, is dependent on the ventilatory strategy and does not give information on the adequacy of cerebral oxygenation.

An 'ideal' parameter to monitor the adequacy of oxygenation and circulation during CPR and ALS would have the following characteristics: easily (non-invasively) measured, continuous rather than intermittent information, and neither requirement of pulsatile flow nor interruption of chest compressions. Last but not least, it
Ciomed Central 
should provide information on the oxygenation of vital organs (heart, kidney, brain).

Cerebral oximetry, based on near-infrared spectroscopy (NIRS) technology, provides information on brain oxygenation and the adequacy of cerebral perfusion [2]. It measures regional cerebral oxygen saturation at the microvascular level (arterioles, venules and capillaries) [3-8]. There have been previous efforts to use cerebral oximetry during CPR with conflicting results [9-11]. Recent developments allow the monitoring of absolute cerebral tissue oxygen saturations $\left(\mathrm{SctO}_{2}\right)$, without the need for calibration (FORE-SIGHT ${ }^{\mathrm{TM}}$ technology) [12]. The EQUANOX Advance $^{\mathrm{TM}}$ uses similar technology [13], but has the advantage of being portable and as such is more user friendly in the pre-hospital setting. Moreover, the EQUANOX $^{\mathrm{TM}}$ technology reveals minimal extracranial contamination compared to other commercially available NIRS technologies [14]. Because of these promising properties (absolute saturation monitoring and transportable monitoring device), we tested the feasibility of both technologies in the CPR setting.

\section{Materials and methods}

In this observational study, data on cerebral tissue oxygen saturation was collected during in- and out-of-hospital cardiac arrest. The $\mathrm{SctO}_{2}$ values were not blinded to the attending emergency physicians but were not used in any treatment protocol or therapeutic decision. The study was approved by the Committee for Medical Ethics, Ziekenhuis Oost-Limburg, Genk, Belgium. Requirement for informed patient consent was waived because of the emergency setting.

\section{Cerebral tissue oxygen saturation}

Two emergency physicians, members of the medical emergency intervention team, used non-invasive cerebral monitoring during ALS for patients suffering from cardiac arrest (CA). Initially, a FORE-SIGHT ${ }^{\mathrm{TM}}$ monitor (CAS Medical Systems, Branford, CT, USA) was transported to the scene of CA. Due to its weight $(9.8 \mathrm{~kg})$, a third person, not taking part in the medical rescue intervention, carried the monitor. On arrival, bilateral NIRS sensors were applied on the patient's forehead. From December 2011 on, the EQUANOX Advance ${ }^{\mathrm{TM}}$ monitor (Nonin Medical Inc., Plymouth, MN, US) was used. Since this monitor is light $(0.9 \mathrm{~kg})$ and easily transportable, aid from a third person was not necessary. To minimize time delay, only one sensor was applied on the patient's right forehead. With both monitoring devices, $\mathrm{SctO}_{2}$ values were electronically collected from arrival until termination of CPR (or until transfer to the emergency unit of the hospital). With both technologies, protective adhesive tape was applied over the sensor(s) in order to minimize possible external light interference.

\section{Cardiopulmonary resuscitation}

Resuscitation procedures were performed in accordance with the Guidelines of the European Resuscitation Council. During ALS, patients were monitored with three-lead ECG and end tidal $\mathrm{CO}_{2}\left(\mathrm{ETCO}_{2}\right)$. Once ROSC had been established, pulse oximetry and non-invasive blood pressure were monitored. In one patient, suffering from inhospital cardiac arrest, invasive blood pressure monitoring was available during ALS.

\section{Statistical analysis}

Statistical analysis was performed using SPSS V19.0 (SPSS Inc, Chicago, IL, USA). Equal distribution was tested using the Kolmogorov-Smirnov test. Values for cerebral oxygen saturation at each time point were compared using the independent $\mathrm{t}$-test. The results are represented as mean ( \pm standard deviation). A $P$-value below 0.05 was considered statistically significant.

\section{Results and discussion}

In sixteen 16 cardiac arrest patients, NIRS monitoring was applied during CPR (five with FORE-SIGHT ${ }^{\mathrm{TM}}$ and eleven with EQUANOX Advance ${ }^{\mathrm{TM}}$ technology). Relevant differences between the two technologies are listed in Table 1.

In two patients (EQUANOXTM), it was impossible to obtain a value within the first three minutes of monitoring, and no further attempts were made to monitor $\mathrm{SctO}_{2}$. Therefore, the results of only 14 patients will be reported.

Three of the five patients monitored with the FORESIGHT ${ }^{\mathrm{TM}}$ monitor suffered from in-hospital cardiac arrest (IHCA), while the majority of patients (seven out of nine) monitored with the EQUANOX ${ }^{\mathrm{TM}}$ monitor suffered from out-of-hospital cardiac arrest (OHCA). Two patients (both OHCA victims) monitored with the FORE-SIGHTTM monitor survived (ROSC $>20$ minutes). ROSC was observed in four patients (three OHCA and one IHCA) monitored with the EQUANOX ${ }^{\mathrm{TM}}$ monitor (Table 2).

\begin{tabular}{lll}
$\begin{array}{l}\text { Table } 1 \text { Differences between EQUANOXTM and } \\
\text { FORE-SIGHTTM monitors }\end{array}$ & \\
\hline & EQUANOX'MM & FORE-SIGHTTM \\
\hline Dimensions (mm) & 180 & 203 \\
$\quad$ height & 305 & 203 \\
$\quad$ width & 130 & 330 \\
$\quad$ depth & 0.9 & 9.8 \\
Weight (kg) & \pm 10 & \pm 32 \\
Time to first value (seconds) & 4 & 2 \\
Response time (seconds) & $>3$ & 1.5 \\
Battery time (hours) & $6.8 \% \pm 6$ & $11.8 \% \pm 5.3$ \\
Extracranial contamination ${ }^{\text {a }}$ & no & yes \\
Trouble shoot menu &
\end{tabular}

${ }^{a}$ Extracranial contamination was determined as a decrease in cerebral oxygen saturation during inflation of a pneumatic head cuff compared to baseline values [14]. 
Table 2 Cerebral oxygen saturation during cardiopulmonary resuscitation

\begin{tabular}{|c|c|c|c|c|c|c|c|}
\hline Patient & $\begin{array}{l}\mathrm{OH} / \\
\mathrm{IH}\end{array}$ & $\begin{array}{l}\mathrm{FS} / \\
\mathrm{EQ}\end{array}$ & ROSC? & $\begin{array}{l}\text { Start value } \mathrm{SctO}_{2} \\
(\%)\end{array}$ & $\begin{array}{l}\text { Highest } \mathrm{SctO}_{2}(\%) \text { during } \\
\text { CPR }\end{array}$ & $\begin{array}{l}\text { Highest } \mathrm{SctO}_{2}(\%) \text { during } \\
\text { ROSC }\end{array}$ & $\begin{array}{l}\mathrm{SctO}_{2}(\%) \text { before } \\
\text { transport }\end{array}$ \\
\hline 1 & $\mathrm{OH}$ & FS & Yes & 33 & 38 & 73 & 67 \\
\hline 4 & $\mathrm{OH}$ & FS & Yes & 44 & 53 & 61 & 60 \\
\hline 6 & $\| \mathrm{H}$ & EQ & Yes & 15 & 58 & 81 & 82 \\
\hline 11 & $\mathrm{OH}$ & EQ & Yes & 40 & 41 & 51 & 47 \\
\hline 13 & $\mathrm{OH}$ & EQ & Yes & 5 & 10 & 58 & 65 \\
\hline 14 & $\mathrm{OH}$ & EQ & yes & 37 & 55 & 67 & 46 \\
\hline $\begin{array}{l}\text { Mean }( \pm \\
\text { SD) }\end{array}$ & & & & $\begin{array}{l}29 \\
15\end{array}$ & $\begin{array}{l}43 \\
18\end{array}$ & $\begin{array}{l}65 \\
11 \\
\end{array}$ & $\begin{array}{l}61 \\
13\end{array}$ \\
\hline Patient & $\begin{array}{l}\mathrm{OH} / \\
\mathrm{IH}\end{array}$ & $\begin{array}{l}\mathrm{FS} / \\
\mathrm{EQ}\end{array}$ & ROSC? & $\begin{array}{l}\text { Startvalue } \mathrm{SctO}_{2} \\
(\%)\end{array}$ & $\begin{array}{l}\text { Highest } \mathrm{SctO}_{2}(\%) \text { during } \\
\text { CPR }\end{array}$ & $\begin{array}{l}\text { Highest } \mathrm{SctO}_{2}(\%) \text { during } \\
\text { ROSC }\end{array}$ & $\mathrm{SctO}_{2}(\%)$ at end CPR \\
\hline 2 & $\mathbb{I H}$ & FS & No & 47 & 45 & & 36 \\
\hline 3 & $\mathbb{H}$ & FS & No & 52 & 61 & & 35 \\
\hline 5 & $\mathbb{H}$ & FS & No & 51 & 52 & & 41 \\
\hline 7 & $\mathrm{OH}$ & EQ & No & 3 & 38 & & 0 \\
\hline 8 & $\mathrm{OH}$ & EQ & No & 14 & 61 & & 11 \\
\hline 9 & $\| \mathrm{H}$ & EQ & No & 7 & 24 & & 8 \\
\hline 10 & $\mathrm{OH}$ & EQ & No & 0 & 35 & & 25 \\
\hline 12 & $\mathrm{OH}$ & EQ & No & 30 & 42 & & 36 \\
\hline $\begin{array}{l}\text { Mean }( \pm \\
\text { SD) }\end{array}$ & & & & $\begin{array}{l}25 \\
22\end{array}$ & $\begin{array}{l}45 \\
13\end{array}$ & & $\begin{array}{l}24 \\
16\end{array}$ \\
\hline
\end{tabular}

EQ, Equanox Advance technology; FS, Fore-Sight technology; IH, in-hospital cardiac arrest; OH, out-of-hospital cardiac arrest; ROSC, return of spontaneous circulation; $\mathrm{SctO}_{2}$, regional cerebral tissue oxygen saturation.

With both technologies, stable NIRS signals and reliable $\mathrm{SctO}_{2}$ values were obtained within the first minute of sensor application, except for both patients previously described and excluded from further analysis.

Starting $\mathrm{SctO}_{2}$ values (during basic life support) were between $0 \%$ and $51 \%$, with a mean value of $27 \%( \pm 19)$ (Table 2). Mean starting $\mathrm{SctO}_{2}$ for IHCA was $34 \%( \pm 22)$ whereas mean starting $\mathrm{SctO}_{2}$ in $\mathrm{OHCA}$ was $23 \%( \pm 17)$, which was not statistically significant $(P=0.296)$. Mean starting $\mathrm{SctO}_{2}$ in survivors was $29 \%( \pm 15)$ which was not significantly different from mean $\mathrm{SctO}_{2}$ in non-survivors $(25 \% \pm 22)(P=0.748)$. Mean time of CPR before the first $\mathrm{SctO}_{2}$ value was monitored was 29 minutes $( \pm 9)$ in OHCA patients and 16 minutes $( \pm 6)$ in IHCA patients (Table 3).

The highest $\mathrm{SctO}_{2}$ values observed during CPR efforts were between $10 \%$ and $61 \%$, with a mean value of $44 \%$ ( \pm 15$)$. Highest $\mathrm{SctO}_{2}$ values during CPR were neither significantly different between OHCA patients $(41 \% \pm 15)$ and IHCA patients $(48 \% \pm 15 ; P=0,442)$ nor between survivors $(43 \% \pm 18)$ and non-survivors $(45 \pm 13 ; P=0.778)$ of CA.

ROSC >20 minutes (survivors) was observed in six patients (five OHCA, one IHCA). In the five OHCA patients, highest $\mathrm{SctO}_{2}$ values after $\mathrm{ROSC}$ were between $51 \%$ and $73 \%$ with a mean value of $62 \%( \pm 8)$. The only IHCA-survivor showed $\mathrm{SctO}_{2}$ values of $81 \%$ after ROSC. In these CA-survivors, $\mathrm{SctO}_{2}$ values before transfer to the emergency unit were between $46 \%$ and $67 \%$ with a mean $\mathrm{SctO}_{2}$ value of $57 \%( \pm 10)$.

In OHCA patients where any further CPR effort was terminated, $\mathrm{SctO}_{2}$ values at the stop of CPR were between 0 and $36 \%$, with a mean $\mathrm{SctO}_{2}$ value of $18 \%$ ( \pm 16$)$. In IHCA patients, $\mathrm{SctO}_{2}$ values were between $8 \%$ and $41 \%$ (mean $30 \% \pm 15)$ when CPR was stopped, which was not different from the OHCA patients $(P=0.311)$ (Table 2). $\mathrm{SctO}_{2}$ values at the end of CPR were significantly lower $(P=$ 0.001) in patients not surviving CA compared with those who were transferred to the emergency unit.

As $\mathrm{SctO}_{2}$ monitoring during CPR provides continuous information during extremely difficult and rapidly changing conditions, relevant information from $\mathrm{SctO}_{2}$ during the

Table 3 Patient Characteristics

\begin{tabular}{lccc}
\hline & $\begin{array}{c}\text { All } \\
\text { patients }\end{array}$ & OHCA & IHCA \\
\hline Number & 14 & 9 & 5 \\
Age, years $( \pm S D)$ & $66(20)$ & 65 & 67 \\
Male, number & 10 & 6 & 4 \\
ROSC $>20$ minutes & 6 & 5 & 1 \\
Time between CA and first $\mathrm{SctO}_{2}$ value, & $25(10)$ & $29(9)$ & $16(6)$
\end{tabular}
min. ${ }^{a}$

athe exact time frame is missing in a number of patients; results are presented as mean $( \pm \mathrm{SD})$. IHCA, in-hospital cardiac arrest; min., minutes; OHCA, out-of-hospital cardiac arrest; ROSC, return of spontaneous circulation. 
CPR efforts is further elucidated by presenting the data of four individual patients (Figures 1, 2, 3, and 4).

This is the first report on the use of the ForeSight ${ }^{\mathrm{TM}}$ and EQUANOX Advance ${ }^{\mathrm{TM}}$ technology during in- and out-ofhospital CPR. Both technologies use four precise infrared wavelengths to maximize the accuracy of oxyhemoglobin and de-oxyhemoglobin measurement and to enable absolute oxygen saturation monitoring (and not just trend-only monitoring). In a recent comparison of accuracy performance (referring to weighted $\mathrm{CO}$-oximeter reference values), the FORE-SIGHTTM monitor measured cerebral oxygenation most precisely, followed by the EQUANOX Advance ${ }^{\mathrm{TM}}$ monitor [15], providing increased confidence in the utilization of this technology in the CPR setting.

Due to the continuous, pulseless wave analysis of both technologies, we were able to monitor the cerebral oxygen saturation in nine OHCA-patients and five IHCA-patients during CPR with two different NIRS devices. The most important difference between the technologies is the respective weight of the monitors. The EQUANOX ${ }^{\mathrm{TM}}$ monitoring device is light $(0.9 \mathrm{~kg})$ and, therefore, the most suited for use during out-of-hospital CPR.

Newman et al. already assessed the feasibility of NIRS to measure cerebral perfusion during OHCA [9]. However, they rarely detected cerebral perfusion or cerebral oxygen saturation using the Invos $-3000^{\circledR}$ technology during CPR. A longer time interval from arrest to initial cerebral

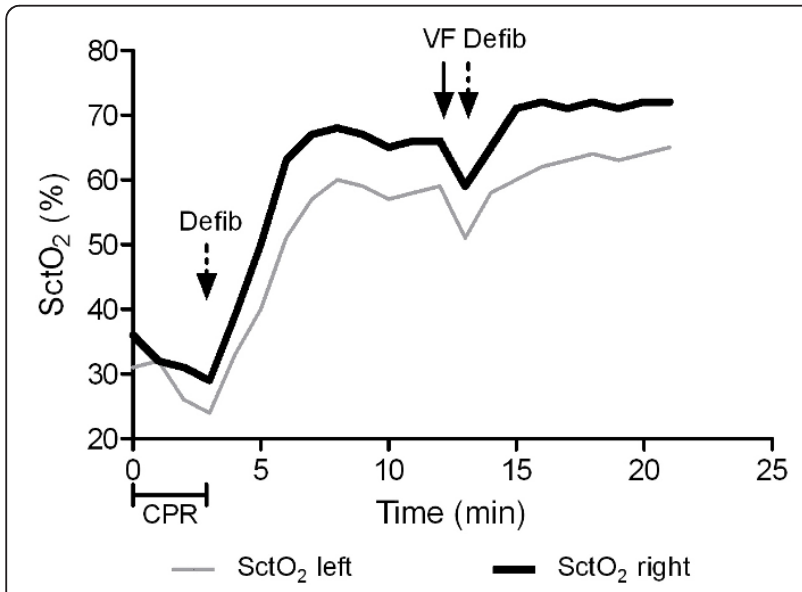

Figure 1 Cerebral tissue oxygen saturation (SctO2 (\%)) (monitored with FORE-SIGHTTM technology) during out-ofhospital cardiac arrest (patient 1). After 15 minutes of BLS, first measured $\mathrm{SctO}_{2}$ values were $31 \%$ and $38 \%$ over the left (grey line) and right (black line) fontal region, respectively. Defibrillation (dotted arrow) resulted in ROSC and an immediate increase in $\mathrm{ScOO}_{2}$ to $60 \%$ (left) and 69\% (right). During preparation for transport, ventricular fibrillation (arrow) reoccurred and was accompanied with an immediate decrease in $\mathrm{SctO}_{2}$. Again, defibrillation (dotted arrow) resulted in sinus rhythm and $\mathrm{SctO}_{2}$ values above $65 \%$. BLS, basic life support; CPR, cardiopulmonary resuscitation; Defib, defibrillation; VF, ventricular fibrillation.

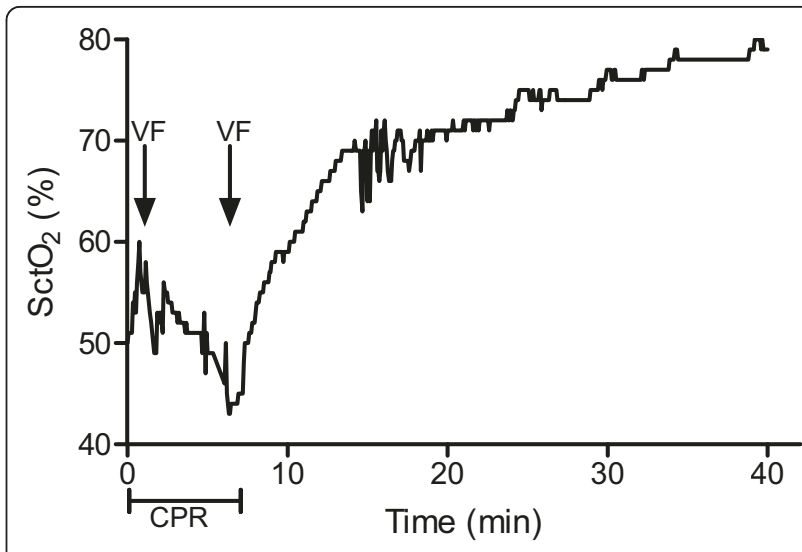

Figure 2 Cerebral tissue oxygen saturation $\left(\mathrm{SctO}_{2}(\%)\right)$ (monitored with EQUANOX Advance ${ }^{\mathrm{TM}}$ technology) in a patient (patient 6) who collapsed at ER entrance. The sensor was applied after six minutes of CPR and two defibrillation attempts. SctO 2 started at $50 \%$ and increased to $60 \%$, right before ventricular fibrillation reoccurred (arrows). When ROSC was achieved, $\mathrm{SctO}_{2}$ increased immediately above $70 \%$. CPR, cardiopulmonary resuscitation; ROSC, return of spontaneous circulation; VF, ventricular fibrillation.

oxygen saturation measurements may partially explain the difference between their OHCA report and previous experience during in-hospital CPR [10,11].

Recently, several papers were dedicated to the use of INVOS $^{\circledR}$-NIRS technology in the post-CA area, indicating its potential role in predicting survival and neurological outcome after CA. One of the earliest, although small, OHCA studies demonstrated that all patients surviving for one week achieved a significantly higher median $\mathrm{rSO}_{2}$ (regional brain oxygen saturation) during CPR efforts than non-survivors [16]. Also, Ito et al. monitored $\mathrm{rSO}_{2}\left(\mathrm{INVOS}^{\circledR}\right.$ technology) and noted that any $\mathrm{rSO}_{2}$ value below $25 \%$, observed on hospital admission in a post-CA patient without ROSC (despite continued CPR efforts), could be interpreted as a potential indicator of futile resuscitation attempts $[17,18]$. Kämäräinen et al. reported on $\mathrm{rSO}_{2}$ (INVOS ${ }^{\circledR}$ technology) and concluded that improving CPR quality did not result in a significant increase in $\mathrm{rSO}_{2}$ [19]. It should be noted that they described substantial difficulties in reliable recordings of $\mathrm{rSO}_{2}$ data with INVOS $5100 \mathrm{C}^{\circledR}$ technology as $59 \%$ of their 30 -second data had artifacts making quantification of $\mathrm{rSO}_{2}$ impossible. Most recently, Parnia et al. (using $\mathrm{INVOS}^{\mathbb{B}}$ ) concluded that IHCA-patients with ROSC had an $\mathrm{rSO}_{2}$ above $30 \%$ for $>50 \%$ of their CPR duration, whereas non-survivors had an $\mathrm{rSO}_{2}$ that was below $30 \%$ for $>50 \%$ of their CPR period $[20,21]$. It therefore stands to reason that cerebral oximetry may have a role in predicting ROSC and the optimization of cerebral oxygenation during cardiac arrest. 

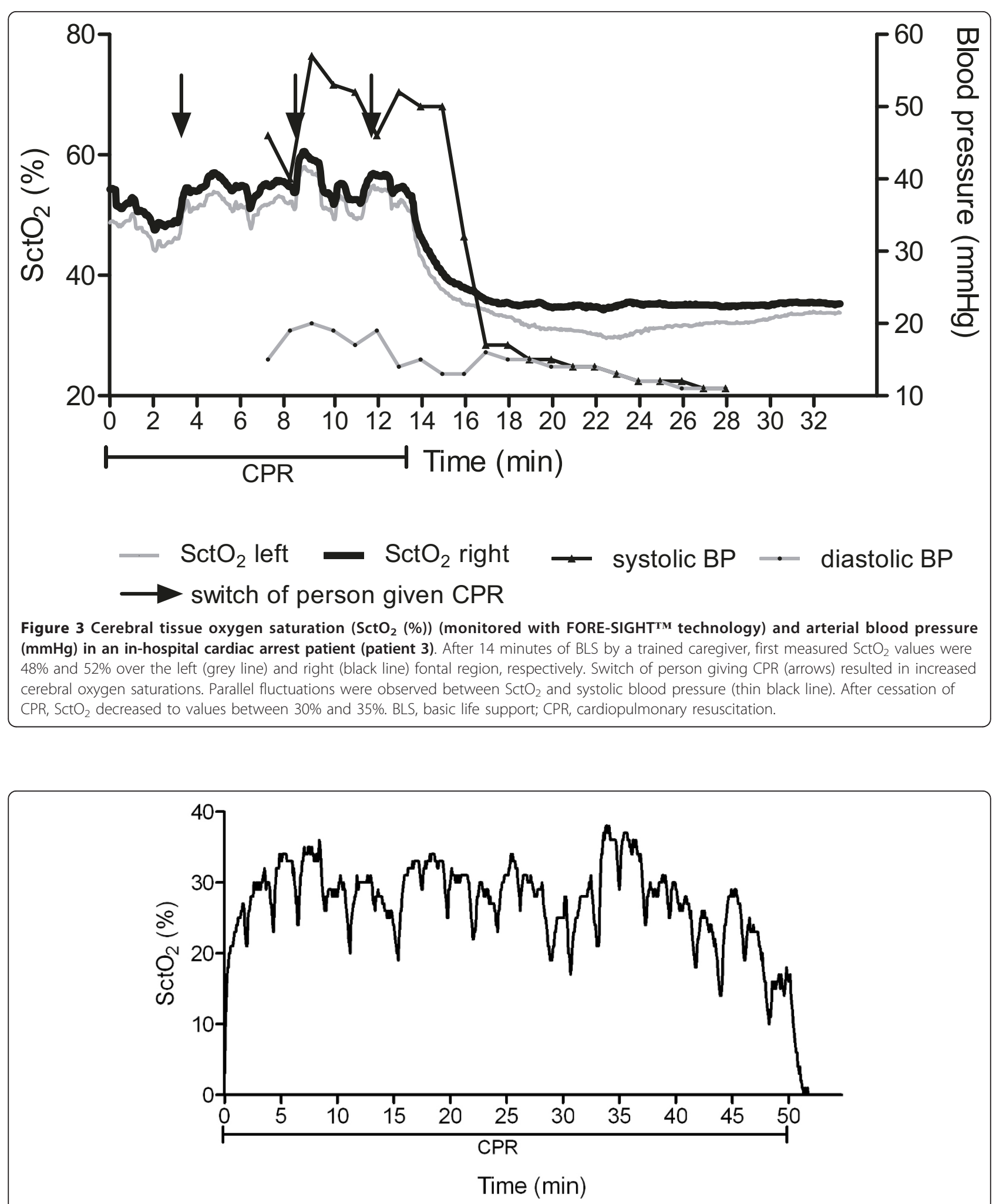

Figure 4 Cerebral tissue oxygen saturation $\left(\mathrm{SctO}_{2}(\%)\right)$ (monitored with EQUANOX Advance ${ }^{\mathrm{TM}}$ technology) during out-of-hospital cardiac arrest (patient 7). The starting $\mathrm{SctO}_{2}$ value (after 20 minutes of BLS) was 3\%, but rose quickly to 21\%. The highest measured value during CPR was 38\%. A decrease in $\mathrm{SctO}_{2}$ was observed during rhythm assessment (every 2 minutes). CPR was stopped 50 minutes after arrival of the medical emergency team, without obtaining ROSC. After termination of CPR, SctO ${ }_{2}$ decreased rapidly. BLS, basic life support; CPR, cardiopulmonary resuscitation; ROSC, return of spontaneous circulation. 
In our 14 patients, starting $\mathrm{SctO}_{2}$ values were between $0 \%$ and $52 \%$. This high variability could be explained by the fact that we measured both IHCA and OHCA patients and that there was a high variability in time from collapse to the first monitored $\mathrm{SctO}_{2}$ value in both groups. Furthermore, not all CPR characteristics were available for all patients. Surprisingly, when using the EQUANOX Advance ${ }^{\mathrm{TM}}$ monitor, a starting value of $0 \% \mathrm{SctO}_{2}$ was observed in one patient and an end-of-CPR value of $0 \%$ in another patient. Whereas the EQUANOX Advance ${ }^{\mathrm{TM}}$ monitor displays these $\mathrm{SctO}_{2}$ values of $0 \%$, the lowest $\mathrm{SctO}_{2}$ value observed with the FORE-SIGHTTM monitor was around $30 \%$. Due to the proprietary algorithms behind both cerebral oximetry monitors it is impossible to provide any further explanation at present. More data are needed to elucidate the exact significance of these extremely low values and to exclude any possible interference from technical artifacts.

We observed an immediate increase in $\mathrm{SctO}_{2}$ after ROSC and found significantly higher $\mathrm{SctO}_{2}$ values in patients with permanent ROSC compared to patients in whom no further CPR effort was continued. Furthermore, in four of our patients, new episodes of ventricular fibrillation (Figures 1 and 2) were immediately noted on the $\mathrm{SctO}_{2}$ monitoring, as an extra monitoring device indicated this life-threatening situation with urgent need for CPR.

$\mathrm{SctO}_{2}$ monitoring provides not only a tool for continuous estimation of cerebral oxygenation during the status of no ROSC, but also the ability to assess the efficacy of CPR efforts. We observed parallel increases in systolic arterial pressure during CPR and in $\mathrm{SctO}_{2}$ (Figure 3), illustrating the positive effect of CPR on systolic blood pressure and on cerebral oxygenation. Switch of caregivers during mechanical chest compression, resulted in increased systolic blood pressure and $\mathrm{SctO}_{2}$ (Figure 3). The immediate effect of efficient CPR on cerebral oxygenation is illustrated in the rapid decrease in $\mathrm{SctO}_{2}$ during rhythm analysis (and consequent interruption of CPR) (Figure 4).

Limitations of this study include the small number of patients, which makes it difficult to reach a conclusion on the exact value of $\mathrm{SctO}_{2}$ in CA patients. A second limitation is the fact that we used two different technologies (FORE-SIGHT ${ }^{\mathrm{TM}}$ and EQUANOX Advance ${ }^{\mathrm{TM}}$ ). Although both technologies use four wavelengths and display absolute saturation values (without need for calibration), they do use different (proprietary) algorithms to display their calculated $\mathrm{SctO}_{2}$ values. The EQUANOX Advance ${ }^{\mathrm{TM}}$ oximeter is shown to have less contamination of extracranial vessels compared with the FORE-SIGHT ${ }^{\mathrm{TM}}$ oximeter [14], but for both oximeters, accuracy is without doubt acceptable [15]. These differences in algorithms can probably be used to explain the different values displayed in extreme conditions. The major limitation of this study was that it was designed as a pilot feasibility study and that not all patient or CPR characteristics are available. A future, randomized, multicenter study will be initiated on the use of NIRS during CPR with the inclusion of all CPR data following the Utstein CPR data registration. Finally, larger and properly designed studies will have to elucidate the potential role of $\mathrm{SctO}_{2}$ monitoring during CPR.

\section{Conclusions}

In conclusion, using FORE-SIGHTTM and EQUANOX ${ }^{\mathrm{TM}}$ technology, it is possible to monitor the $\mathrm{SctO}_{2}$ during CPR after IHCA and OHCA. Moreover, changes in cerebral oxygen saturation seem to vary with the quality of chest compressions reflecting changes in cerebral oxygenation. Future studies on the prognostic role of cerebral oximetry during CPR are needed.

\section{Key messages}

- NIRS technologies allow measurement of $\mathrm{SctO}_{2}$ during CPR.

- These technologies may in the future prove to fulfill the need for better monitoring during CPR.

- $\mathrm{SctO}_{2}$ values are the earliest warning signs of impending changes in cerebral oxygenation during/ after CPR.

\section{Abbreviations}

ALS: advanced life support; BLS: basic life support; CA: cardiac arrest; CPR: cardiopulmonary resuscitation; ECG: electrocardiography; NIRS: near infrared spectroscopy; IHCA: in-hospital cardiac arrest; OHCA: out-of-hospital cardiac arrest; ROSC: return of spontaneous circulation; $\mathrm{SctO}_{2}$ : absolute cerebral tissue oxygen saturation; $\mathrm{rSO}_{2}$ :regional brain oxygen saturation

\section{Authors' contributions}

IM and CD made substantial contributions to the conception and design of the study, and drafted the manuscript. JD, WB and FJ participated in the design of the study and helped to draft the manuscript. SS and KL were involved in the realization of the study as members of the medical emergency unit. GV and RH were involved in the internal reviewing process. All authors read and approved the final manuscript for publication.

\section{Competing interests}

The authors declare that they have no competing interests.

\section{Acknowledgements}

The authors are indebted to all physicians and emergency medical technicians involved in the prehospital care of the patients reported in this study, as well as to the whole nursing staff of the department of Emergency Medicine ZOL, Genk (Belgium). This study is part of the Limburg Clinical Research Program (LCRP) UHasselt-ZOL-Jessa, supported by the foundation Limburg Sterk Merk, Hasselt University, Ziekenhuis Oost-Limburg and Jessa Hospital.

\section{Author details}

'Department of Anesthesiology, Intensive Care, Emergency Medicine \& Pain Therapy, Ziekenhuis Oost-Limburg, Schiepse Bos 6, 3600 Genk, Belgium. ${ }^{2}$ Department of Cardiology, Ziekenhuis Oost-Limburg, Schiepse Bos 6, 3600 Genk, Belgium. ${ }^{3}$ Faculty of Medicine and Life Sciences, Hasselt University, Agoralaan, 3590 Diepenbeek, Belgium. 


\section{References}

1. Nolan JP, Soar J, Zideman DA, Biarent D, Bossaert LL, Deakin C, Koster RW, Wyllie J, Böttiger B, on behalf of the ERC Guidelines Writing Group: European Resuscitation Council Guidelines for Resuscitation 2010 Section 1. Executive summary. Resuscitation 2010, 81:1219-1276.

2. Ferrari M, Mottola L, Quaresima V: Principles, techniques, and limitations of near infrared spectroscopy. Can J Appl Physiol 2004, 29:463-487.

3. Benni PB, Chen B, Dykes FD, Wagoner SF, Heard M, Tanner AJ, Young TL, Rais-Bahrami K, Rivera O, Short BL: Validation of the CAS neonatal NIRS system by monitoring vv-ECMO patients: preliminary results. Adv Exp Med Biol 2005, 566:195-201.

4. Watzman HM, Kurth CD, Montenegro LM, Rome J, Steven JM, Nicolson SC: Arterial and venous contributions to near-infrared cerebral oximetry. Anesthesiology 2000, 93:947.

5. Madsen PL, Secher NH: Near-infrared oximetry of the brain. Prog Neurobiol 1999, 58:541-560.

6. Owen-Reece $\mathrm{H}$, Smith M, Elwell C, Goldstone J: Near infrared spectroscopy. Br J Anaesth 1999, 82:418-426.

7. Jobsis FF: Noninvasive, infrared monitoring of cerebral and myocardial oxygen sufficiency and circulatory parameters. Science 1977, 198:1264.

8. Fischer GW: Recent advances in application of cerebral oximetry in adult cardiovascular surgery. Semin Cardiothorac Vasc Anesth 2008, 12:60-69.

9. Newman DH, Callaway CW, Greenwald IB, Freed J: Cerebral oximetry in out-of-hospital cardiac arrest: standard CPR rarely provides detectable hemoglobin-oxygen saturation to the frontal cortex. Resuscitation 2004, 63:189-194.

10. Paarmann $H_{\text {, Heringlake } M}$, Sier $H$, Schon J: The association of noninvasive cerebral and mixed venous oxygen saturation during cardiopulmonary resuscitation. Interact Cardiovasc Thorac Surg 2010, 11:371-373.

11. Nagdyman N, Fleck TP, Ewert P, Abdul-Khaliq H, Redlin M, Lange PE: Cerebral oxygenation measured by near-infrared spectroscopy during circulatory arrest and cardiopulmonary resuscitation. Br J Anaesth 2003, 91:438-442.

12. MacLeod D, Ikeda K, Vacchiano C: Simultaneous comparison of FORESIGHT and INVOS cerebral oximeters to jugular bulb and arterial cooximetry measurements in healthy volunteers. Anesth Analg 2009, 108(SCA suppl):1-104.

13. MacLeod D: Development and validation of a cerebral oximeter capable of absolute accuracy. J Cardiothorac Vasc Anesth 2012, 26:1007-1014.

14. Davie SN, Grocott HP: Impact of extracranial contamination on regional cerebral oxygen saturation: a comparison of three cerebral oximetry technologies. Anesthesiology 2012, 116:834-840.

15. Bickler PE, Feiner JR, Eilers H, Rollins M: Performance of 5 Cerebral Oximeters During Hypoxia in Healthy Volunteers. American Society of Anesthesiologists Annual Meeting Poster session 2011.

16. Müllner $M$, Sterz $F$, Binder $M$, Hirschl $M$, Janata $K$, Laggner $A$ : Near infrared spectroscopy during and after cardiac arrest-preliminary results. Clin Intensive Care 1995, 6:107.

17. Ito N, Nanto S, Nagao K, Hatanaka T, Kai T: Regional cerebral oxygen saturation predicts poor neurological outcome in patients with out-ofhospital cardiac arrest. Resuscitation 2010, 81:1736-1737.

18. Ito N, Nanto S, Nagao K, Hatanaka T, Nishiyama K, Kai T: Regional cerebra oxygen saturation on hospital arrival is a potential novel predictor of neurological outcomes at hospital discharge in patients with out-ofhospital cardiac arrest. Resuscitation 2012, 83:46-50.

19. Kamarainen A, Sainio M, Olkkola KT, Huhtala H, Tenhunen J, Hoppu S: Quality controlled manual chest compressions and cerebral oxygenation during in-hospital cardiac arrest. Resuscitation 2012, 83:138-142.

20. Parnia S, Nasir A, Shah C, Patel R, Mani A, Richman P: A feasibility study evaluating the role of cerebral oximetry in predicting return of spontaneous circulation in cardiac arrest. Resuscitation 2012, 83:982-985.

21. Parnia S: Cerebral oximetry-the holy grail of non-invasive cerebral perfusion monitoring in cardiac arrest or just a false dawn? Resuscitation 2012, 83:11-12.

doi:10.1186/cc12546

Cite this article as: Meex et al:: Feasibility of absolute cerebral tissue oxygen saturation during cardiopulmonary resuscitation. Critical Care 2013 17:R36.

\section{Submit your next manuscript to BioMed Central and take full advantage of:}

- Convenient online submission

- Thorough peer review

- No space constraints or color figure charges

- Immediate publication on acceptance

- Inclusion in PubMed, CAS, Scopus and Google Scholar

- Research which is freely available for redistribution 